\title{
COMPARISON OF METHODS FOR DETERMINATION OF SULPHUR IN RECLAIMED SAND
}

\author{
1'Jiřina VONTOROVÁ, '1Jaroslav BEŇO, ${ }^{1}$ Martin KRYSMÁNEK, ${ }^{1}$ Karolina SLAMOVÁ \\ ${ }^{1}$ VSB - Technical University of Ostrava, Ostrava, Czech Republic, EU, iirina.vontorova@vsb.cz
}

https://doi.org/10.37904/metal.2020.3453

\begin{abstract}
The article deals with the determination of sulphur contents in different types of foundry furan no-bake reclaims from different suppliers using two different methods - combustion elemental analysis and gravimetrically. The first of these methods is the standard fast instrumental method. The work aimed to prove if it could be replaced by the method of traditional analysis, which does not have high demands on instruments.
\end{abstract}

Keywords: Furan no-bake, reclamation, sand, determination of sulphur content

\section{INTRODUCTION}

Using furan no-bake (FNB) mixtures started in the 1950s. The popularity of these mixtures increased in the 1980s, making them one of the most widely used resin binders. It is currently the best-selling no-bake system in the world [1]. This no-bake mixture consists of three components. It is composed of an acid catalyst together with a reactive furan binder (resin) and sand. The dark-coloured liquid resin acts as a binder for the sand particles and the catalyst [2]. Optimal process operating temperatures range from 10 to $30{ }^{\circ} \mathrm{C}$. The amount of furan binder used usually ranges from 0.8 and $1.1 \%$, based on the weight of the sand and the kind of the sand. The amount of catalyst ranges from 20 to $60 \%$ of the binder weight.

Moulds/cores made of FNB mixture have high dimensional stability, which allows reducing the production cycle time of the moulds/cores, casting respectively. It saves costs associated with machining, work and energy. Other favourable properties include curing speed, strength, high dimensional accuracy, fast toughness, high production efficiency, excellent surface finish and low labour intensity [3].

The production of core mixtures based on furan also shows some adverse impacts on the environment and the surroundings $[4,5]$. It is accompanied by the formation of undesirable by-products (e.g. emissions, solid waste), which must be recovered, recycled (reclaimed), treated or disposed of. Reclamation of the moulding mixture remains a priority, as it forms the largest volume of waste [6].

Reclamation aims for cleaning the sand from binder residues and other undesirable components (fine and dusty fractions of the sand) and thus obtaining sand of the original grain size and purity. Successful reclamation requires specific steps for the particular system. The reclamation must be so intensive as to remove both the binder residues adhering to the grains and the harmful components which are undesirable when the reclaim is reused [7]. In practice, three main reclamation processes are used: mechanical reclamation, thermal reclamation and wet reclamation [8]. In the case of organic binders application, thermal reclamation is most advantageous because it removes a large amount of organic binder. This method uses high temperatures (from 450 up to $800^{\circ} \mathrm{C}$ based on binder system) with the recoverability of up to $98 \%$ of quality sand. In addition to the optimal removal of organic substances, it also ensures a substantial reduction in the content of undesirable nitrogen and sulphur. However, this variant is the most financially demanding, which is why less expensive mechanical reclamation is used [9].

Sulphur is present in furan catalysts [10]. Organic sulphur-based acids (PTSA, BSA and XSA) are commonly used, and winter catalysts are then supplemented with sulphuric acid. Its high content in a reclaim (above 
about $0.15 \%$ ) can cause the release of modification magnesium in the production of spheroidal graphite cast iron. Magnesium sulphide is formed (magnesium has a higher affinity for sulphur); therefore, the shape of spheroidal graphite is degraded close to casting surface (the surface of the casting has the characteristic of LLG, not LKG). Degradation of graphite in the surface layer is most important for thin-walled castings, where more than $10 \%$ of the total surface of the casting degrades [11]. Sulphur dioxide is formed during casting, which degrades the working environment and can be a source of casting gas defects (exogenous bubbles). The total sulphur content in the reclaimed sand should not exceed 0.15 weight \%. Under optimal conditions, exceeding this value can have a negative effect on the casting $[10,12]$.

\section{EXPERIMENTAL MATERIAL}

Six samples of mechanically reclaimed sand (FNB reclaim) were taken from the foundry production; sampling was taking place over a period of two years (the study of the effect of different catalysts with different free sulphur content). The analysed furan reclaim was a granular, black, heterogeneous material (Figure 1). The individual samples differed in colour, grain size and chemical composition. Different binders, sands and catalysts were used in the preparation of the mixtures (see Table 1). The catalysts contained sulphuric acid, methylbenzenesulphonic acid, p-toluenesulphonic acid and xylenesulphonic acid. The exact chemical composition determined from the safety data sheets of the individual catalysts used is given in the table (Table 2).

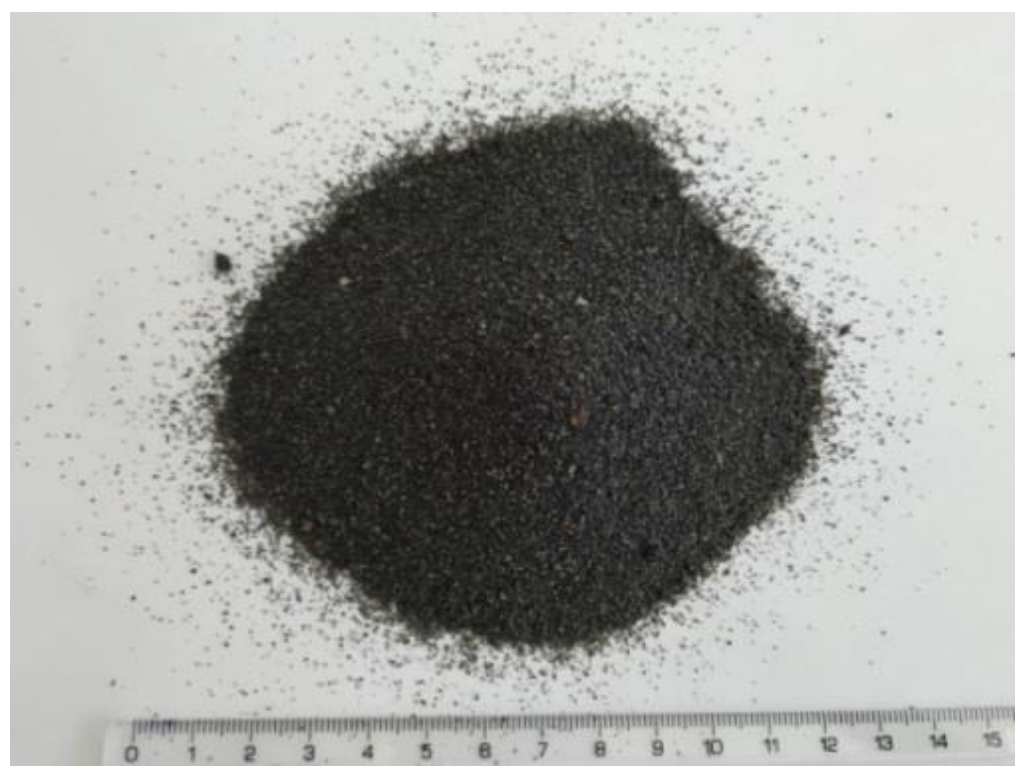

Figure 1 Furan reclaim (Sample 1)

Table 1 Overview of samples with dates of their collection from the foundry

\begin{tabular}{|c|c|c|c|c|}
\hline $\begin{array}{c}\text { Sample } \\
\text { number }\end{array}$ & $\begin{array}{c}\text { Sample } \\
\text { identification }\end{array}$ & Binder identification & $\begin{array}{c}\text { Hardener } \\
\text { identification }\end{array}$ & $\begin{array}{c}\text { Transverse Strength } \\
\text { after 24 h }\end{array}$ \\
\hline 1 & 12.9 .2016 & Askuran FH 040 & Aktivator 100T5D & $2.00 \mathrm{MPa}$ \\
\hline 2 & 12.6 .2017 & Kaltharz X850 M1 & Aktivator 100T5D & $1.60 \mathrm{MPa}$ \\
\hline 3 & 27.7 .2017 & Cesafur 2138 & Aktivator 100T5D & $2.07 \mathrm{MPa}$ \\
\hline 4 & 15.9 .2017 & Cesafur 2138 & Aktivator 100T5D & $1.87 \mathrm{MPa}$ \\
\hline 5 & 22.11 .2017 & Permaset 841 & Aktivator 100T3 & $1.93 \mathrm{MPa}$ \\
\hline 6 & 16.02 .2018 & Kaltharz X850 TN012 & Aktivator 100T3 & $2.01 \mathrm{MPa}$ \\
\hline
\end{tabular}


Table 2 Chemical composition of activators

\begin{tabular}{|c|c|c|}
\hline Activator name & Name of the substance contained & Content in weight per cent \\
\hline \multirow{2}{*}{ Aktivator 100 T3 } & p-toluenesulphonic acid & $<65$ \\
\cline { 2 - 3 } & sulphuric acid & $<2$ \\
\hline \multirow{3}{*}{ Aktivator 100 T5D } & methylbenzenesulphonic acid & $<60$ \\
\cline { 2 - 3 } & sulphuric acid & $<1.9$ \\
\hline \multirow{3}{*}{ Aktivator 500 T1 } & p-toluenesulphonic acid & $35-45$ \\
\cline { 2 - 3 } & xylenesulphonic acid & $25-35$ \\
\cline { 2 - 3 } & sulphuric acid & $<3$ \\
\hline
\end{tabular}

\section{EXPERIMENTAL METHODS}

This paper compares two methods for the determination of sulphur in furan reclaim: the commonly used instrumental method - combustion elemental analysis and the gravimetric method.

The determination of the sulphur content in the induction furnace of a combustion elemental analyser (EA) is one of the most sensitive and accurate methods. The ELTA CS 2000 Analyser was used for this purpose. It is possible to determine the total sulphur (and simultaneously also carbon) content in steels, cast irons, nonferrous alloys [13], slags, but also organic materials [14] and nanomaterials [15].

When determining sulphur gravimetrically, the mineralisation of organic compounds is performed first, i.e. conversion of organically bound sulphur into sulphates, then barium sulphate $\left(\mathrm{BaSO}_{4}\right)$ is precipitated from the acid medium with a solution of barium chloride $\left(\mathrm{BaCl}_{2}\right)$ according to the equation: $\mathrm{SO}_{4}^{-2}+2 \mathrm{BaCl}_{2}=\mathrm{BaSO}_{4}+2 \mathrm{Cl}$.

\section{RESULTS AND DISCUSSION}

Combustion elemental analysis is a method standardly used to determine the sulphur contents of foundry products. One of the aims of the research was to verify the repeatability of the determination. Therefore, the samples were measured repeatedly (10x) over two years, and the homogeneity (presence of outliers), normality and independence of the data were assessed. The QC Expert software, the "Basic Statistics" module, was used for statistical evaluation. With the exception of Sample 1 (Table 3), all measurements showed normality, homogeneity and independence of data.

Table 3 The sulphur content of samples determined by combustion method - Sample 1

\begin{tabular}{|c|c|c|}
\hline Date of sampling & Date of measurement & Sulphur content of the sample (wt.\%) \\
\hline \multirow{10}{*}{ 12. 9. 2016} & \multirow{5}{*}{ 25. 8. 2017} & 0.133 \\
\hline & & 0.077 \\
\hline & & 0.104 \\
\hline & & 0.125 \\
\hline & & 0.119 \\
\hline & \multirow{5}{*}{ 15. 2. 2018} & 0.142 \\
\hline & & 0.124 \\
\hline & & 0.129 \\
\hline & & 0.115 \\
\hline & & 0.121 \\
\hline \multicolumn{2}{|c|}{ Average } & 0.119 \\
\hline \multicolumn{2}{|c|}{ Average after omitting the outliers } & 0.124 \\
\hline
\end{tabular}


Figure 2 shows, for example, the probability density curve for Sample 1. From this graph, it is possible to assess the consensus with the normal distribution. The red curve shows the distribution of the measured values. The green curve shows the normal distribution. The graph shows that the curve from the measured values (red) is higher than the model curve (green), which shows a high concentration of values in the same area. The measured values are more concentrated in the right part of the function, so it is a right-hand kurtosis distribution. Extreme values appear in the left part; outliers are reflected by this sign.



Figure 2 Probability density - QC Expert software, module "Basic statistics", results of determination of sulphur content in Sample 1 by combustion elemental analysis

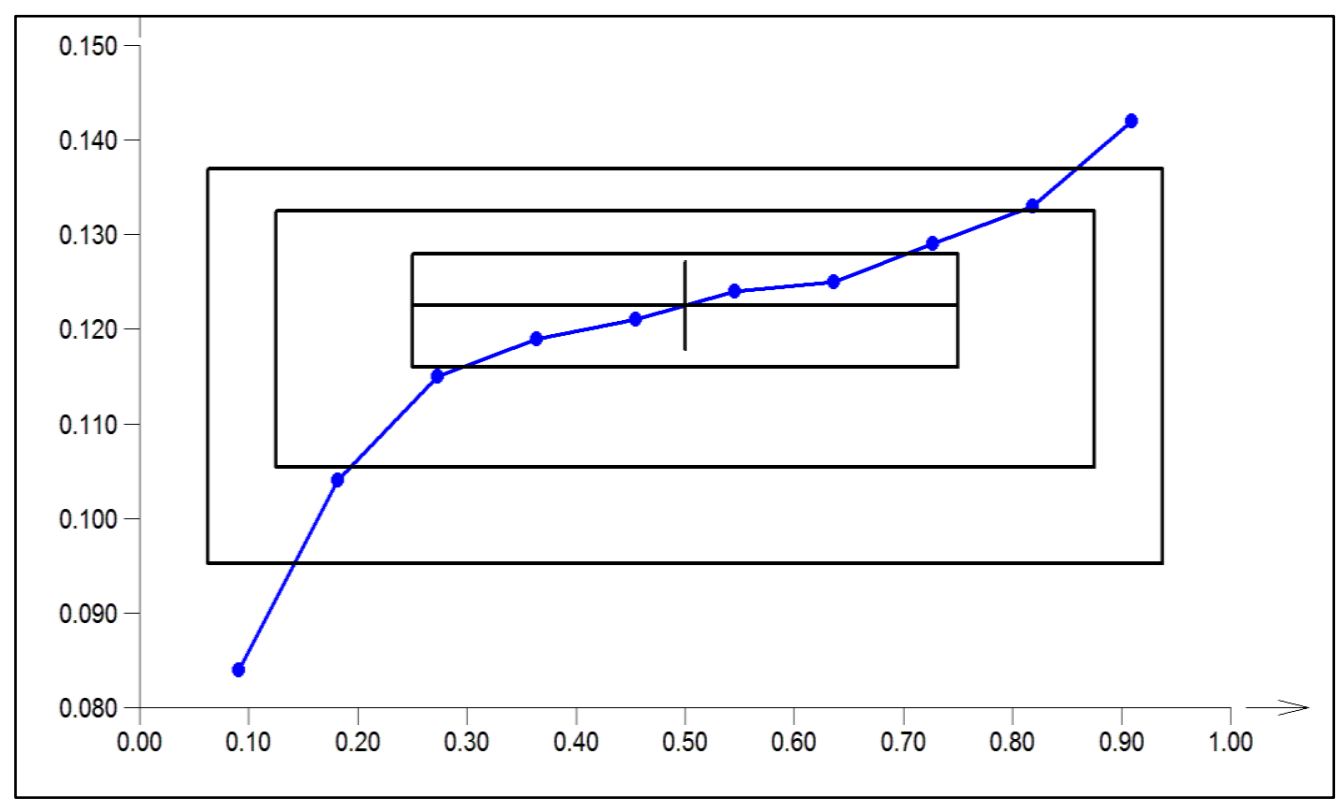

Figure 3 A scatter plot with quantiles - QC Expert software, module "Basic statistics", results of determination of sulphur content in Sample 1 by combustion elemental analysis

Figure 3 shows a scatter plot with quantiles for Sample 1. The slight asymmetry of quantum rectangles indicates an asymmetric distribution. This plot consists of 3 quantile rectangles: quantile (smallest), octile (medium) and sedecile rectangle (largest). Two points that lie outside the largest rectangle were indicated 
as suspected outliers. These points ( 0.077 and 0.142 weight \%) were subjected to the Dean-Dixon test, and it was shown that the maximum value is not outliers, but the value 0.077 is outliers. Therefore, this value (marked in red in Table 3) was omitted from the data for further statistical analysis (see Table 3). If this value is omitted, the data can be considered homogeneous, independent and showing a Gaussian distribution (data normality confirmed).

The second fundamental task was to assess the possibility of replacing combustion elemental analysis with the method of traditional analysis, which is much more time consuming but does not require any special instrumental equipment.

The following table (Table 4) shows the average values determined by both methods. These results were again subjected to statistical testing using QC Expert software - "Comparison of two selections - Pairwise comparison", and it was found that the differences between the two methods are statistically significant and the gravimetric method cannot replace combustion elemental analysis. These results are also graphically confirmed by Figure 4, which shows a correlation graph. The blue line shows the relationship between the results of both methods, the red line shows the unit directive, i.e. the equation $y=x$, for the theoretical case, if the results of both methods were completely equal.

Table 4 Comparison of sulphur determination results by selected methods

\begin{tabular}{|c|c|c|c|}
\hline \multirow{2}{*}{ Sample number } & \multicolumn{2}{|c|}{ Sulphur content in the sample (wt. \%) } & $\begin{array}{c}\text { The difference } \\
\text { between the results of } \\
\text { the methods used }\end{array}$ \\
\cline { 2 - 4 } & EA & Gravimetry & $5 \%$ \\
\hline 1 & 0.124 & 0.13 & $15 \%$ \\
\hline 2 & 0.104 & 0.12 & $17 \%$ \\
\hline 3 & 0.120 & 0.14 & $25 \%$ \\
\hline 5 & 0.112 & 0.14 & $35 \%$ \\
\hline 6 & 0.126 & 0.17 & $25 \%$ \\
\hline average & 0.136 & 0.17 & $\mathbf{2 0} \%$ \\
\hline
\end{tabular}

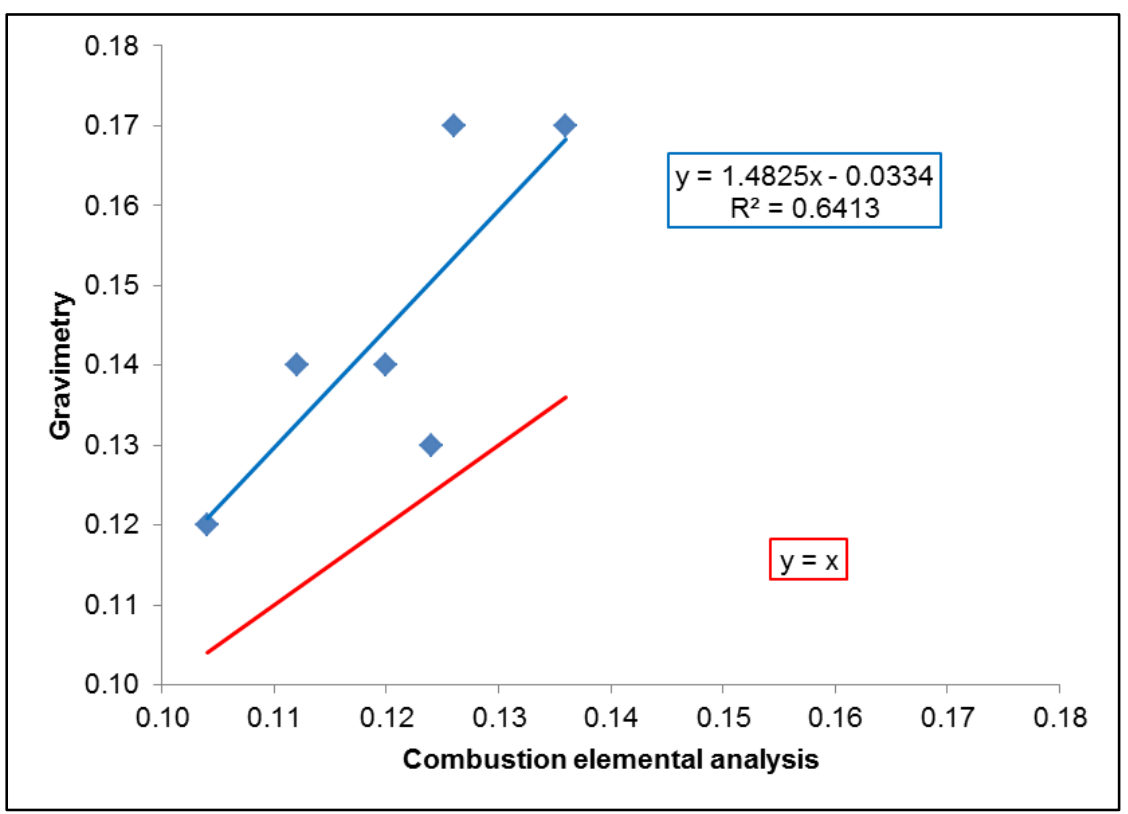

Figure 4 Correlation graph - Comparison of results of combustion elemental analysis and gravimetry 


\section{CONCLUSION}

The main goal of this work was to design and verify a method for determining the sulphur content in furan nobake reclaim with respect to its usability in foundries.

In practice, combustion elemental analysis is used to determine the sulphur content of the FNB reclaim. This method is the most accurate and sensitive. It is also the fastest option in terms of time savings. One of the aims of the work was to assess whether it could be replaced by a gravimetric method, which is not demanding with respect to the instrumental equipment of the laboratory. Six samples of furan reclaims were analysed. Based on the performed analyses and statistical evaluation, it can be said that the methods do not show statistically identical results and that, therefore, the combustion method cannot be replaced by a gravimetric one. The gravimetric method showed higher values for all six samples. This can be caused, for example, by an error in the measurement, since the gravimetric method contains a lot of partial steps before the determination takes place.

The resulting data show that the proportion of sulphur in the reclaim gradually increases (except for the first sampling). This may be due to the changing catalyst along with changes in the temperature during the season. In the winter months, the reclaim contains more sulphur. This is due to the increased addition of sulphuric acid to the mixture during the winter months.

\section{ACKNOWLEDGEMENTS}

This work was supported by the EU Regional Development Fund within the Operational Programme Research, Development and Education under the aegis of Ministry of Education, Youth and Sports of the Czech Republic; Project number CZ.02.1.01/0.0/0.0/17_049/0008426 and by VŠB-Technical University of Ostrava: SP2020/39 and SP2020/44.

\section{REFERENCES}

[1] ACHARYA, S.G., VADHER, J.A, SHELADIYA, M. A Furan No-Bake Binder System Analysis for Improved Casting Quality. International Journal of Metalcasting. 2016, 10(4), pp. 491-499. WOS: 000384434100012.

[2] SINGH, G., SIDDIQUE R. Effect of waste foundry sand (WFS) as partial replacement of sand on the strength, ultrasonic pulse velocity and permeability of concrete. Construction and Building Materials. 2012, 26(1), pp. 416422. WOS: 000295754200050.

[3] ACHARYA, S.G., VADHER, J.A., KOTHARI, K.D. Evaluation of Critical Parameters for Sand Inclusion Defect in FNB Casting. Archives of Foundry Engineering. 2017, 17(1), pp. 5-12. WOS: 000398158200001.

[4] LI, Y.L., WU, G.H., LIU, W.C., CHEN, A.T., ZHANG, L., WANG, Y.X. Effect of reclaimed sand additions on mechanical properties and fracture behavior of furan no-bake resin sand. China Foundry. 2017, 14(2), pp. 128137. WOS: 000399103900008.

[5] BOBROWSKI, A., GRABOWSKA, B. The impact of temperature on furan resin and binders structure Artur Bobrowski, Beata Grabowska. Metallurgy and Foundry Engineering. 2012, 38(1), pp. 73-80. DOI: 10.7494/mafe.2012.38.1.73.

[6] ZANETTI, M.C.,. CLERICI, C., SANDRIN, D., OPERTO, M. Employment of foundry wastes. Developments in Mineral Processing. Elsevier, 2000, pp. C12a-9-C12a-14. DOI: 10.1016/S0167-4528(00)80092-7.

[7] CHRÁST, J. Slévárenská zařízení. Brno: Akademické nakladatelství CERM, 2006.

[8] ZANETTI, M.C., FIORE S. Foundry processes: the reclamation of green moulding sands for core operations. Resources, Conservation and Recycling. 2003, 38 (3), pp. 243-254. WOS: 000183120400004.

[9] BEDNÁŘOVÁ, V. Recyklace slévárenských odpadů : regenerace formovacích směsí. Ostrava: VŠB - Technická univerzita Ostrava, 2004.

[10] GRABOWSKA, B., HOLTZER, M., DANKO, R., GORNY, M., BOBROWSKI, A., OLEJNIK, E. New BioCo binders containing biopolymers for foundry industry. Metalurgija, 2013, 52(1), pp 47-50. WOS: 000308848100010 
[11] DAŃKO, R., HOLTZER, M., GÓRNY, M., ŻYMANKOWSKA-KUMON, S. Effect of Reclamation on the Skin Layer of Ductile Iron Cast in Furan Molds. Journal of Materials Engineering and Performance. 2013, 22(11), pp. 35923600. WOS: 000326888500044.

[12] DAŃKO, R., HOLTZER, M., DAŃKO, J. Investigations of Physicochemical Properties and Thermal Utilisation of Dusts Generated in the Mechanical Reclamation Process of Spent Moulding Sands. Archives of Metallurgy and Materials. 2015, 60(1), pp. 313-318. WOS: 000352142100050

[13] ČEGAN, T., CAGALA, M., KURSA, M, KAWULOK, P., RUSZ S., JUŘICA, J., VONTOROVÁ, J. Effect of Ti2AIC Particles on the Microstructure and Elevated-Temperature-Deformation Properties of Gamma-TiAl Alloys. Materiali in tehnologije. 2014, 48(6), pp. 831-835. WOS: 000348407500006.

[14] KLIKA, Z, SERENČíšOVÁ, J., KOŽUŠNíKOVÁ, A., KOLOMAZNÍK, I., STUDENTOVÁ, S., VONTOROVÁ, J. Multivariate statistical assessment of coal properties. Fuel Processing Technology. 2014, 128, pp. 119-127. WOS: 000343389900014.

[15] VONTOROVÁ, J., MATĚJKA, V., DĚDKOVÁ, K., PRAUS, P. The method for determination of sulfur content in nanocomposites. NANOCON 2013, 5TH INTERNATIONAL CONFERENCE, 2014, pp. 752-756.

WOS: 000352070900134. 